\title{
Reflections on the Future of Public Transportation
}

\author{
Joel Volinski \\ University of South Florida
}

This issue marks my last as editor of the Journal of Public Transportation. I have retired after a 35-year career in public transportation during which I served as the director of Broward County Transit, a mid-size transit agency in southeast Florida, and for the past 24 years as the director of the National Center for Transit Research within the Center for Urban Transportation Research at the University of South Florida. Retirement usually calls for reflecting on what you accomplished over your career. What I find more interesting to do at this time is to reflect on what the future holds for public transportation. Honestly, the provision of public transportation did not change a great deal during my 35 years as a transit agency director and a university researcher. Yes, advances have been made in alternative fuels, real-time passenger information, more flexible forms of paying fares, the provision of attractive Bus Rapid Transit, the expected implementation of Positive Train Control, the analytics associated with better data, and other things that have helped improve the quality of the service. However, the fundamental form public transportation has taken, in terms of who is providing it and how, has been largely the same since at least the 1970 s.

We are now in what some people call the "Exponential Age." Enormous advances in technology and communications are occurring at a pace never seen or imagined before. Many of the new technological advances are considered disruptive due to their impact on the status quo of how services are currently provided. The development of Transportation Network Companies (TNCs) is a clear example of such disruption as they have taken market share away from traditional taxis, are very likely contributing to declines in transit ridership, and might affect the number of new cars sold by major manufacturers. Even more substantial change and disruption is anticipated with the progress being made in the development of automated and connected vehicles. Projections vary as to when we might see substantial numbers of automated vehicles on the road, but virtually every car manufacturer is preparing as if it could be in a very few years. Long-range transportation policy makers are finding it difficult to plan for a transportation system and travel behavior that will likely be transformed in ways we can only guess about at this time.

\section{(C) 2018 Joel Volinski}

http//dx.doi.org/10.5038/2375-0901.21.1.13

ISSN: 1077-291X | Licenced under Creative Commons License Attribution - Noncommercial 4.0

The Journal of Public Transportation is published by the Center for Urban Transportation Research at the University of South Florida 
In addition to changes in technology and communications, there are also changes in society and demography that need to be considered when looking to the future. The millennial generation is more comfortable with technology than previous generations were, and is open to the possibilities provided through a shared economy where access to mobility is more important than vehicle ownership. Again, we can only guess if this might mean more or less demand for public transportation.

The desire to predict the future for public transportation has become more urgent as ridership has shown distinct signs of decline in the last three years throughout most of the country. Will this decline continue or will transit use go back to levels that existed before the Great Recession and hold steady? Or might ridership grow?

The majority of the urban areas in the United States were not designed or planned with public transit as a priority. Starting with the end of World War II and the beginning of the Interstate Highway System, most of the United States was designed to accommodate the automobile and truck traffic. Most western industrialized nations average at least five times the share of daily trips made by transit in the United States. The number of daily trips on transit has increased somewhat steadily since 1970, from 7.0 billion trips annually to over 10.5 billion trips today, but the per capita utilization of transit has remained stubbornly flat despite a considerable amount of investment in transit infrastructure.

News headlines asking if self-driving vehicles and TNCs might make public transportation obsolete and research papers focusing on the "new mobility" are becoming more prevalent and do not provide much optimism for public transit's future in the United States. Most of the factors that negatively affect current transit ridership are beyond the control of transit agencies. Consider the following factors that almost certainly have contributed to declines in transit ridership:

1. Lower gas prices

2. Telecommuting is the fastest growing segment of "mobility" and now almost equals transit's share of all trips

3. E-commerce (online shopping) reduces the amount of travel necessary to shop, represents $7 \%$ of all purchases, and continues to grow in popularity

4. TNCs such as Uber and Lyft are believed to siphon off at least a small percentage of transit's so-called choice riders

5. Bikesharing is now available in 99 cities with 3,400 stations and $33,000+$ bikes, which is likely contributing to the loss of at least some percentage of inner city transit trips

6. There are now 21 active carsharing programs with 1.4 million members throughout the United States

7. A better economy and more employment once seemed to result in more transit ridership, but now seem to result in more car purchases as income increases and gas prices drop

8. Most colleges and universities provide distance learning through internet-based courses, reducing the amount of travel associated with higher learning

9. Baby boomers are retiring, and retirees and seniors traditionally travel less than they did when they were working 
10. Immigration, which often provides more riders for transit systems, is declining

11. Total service hours were reduced because of the Great Recession and many systems have never reinstituted the same levels of service

12. Population in the United States is growing rapidly in suburban areas that are not transitrich, while it declines or grows only minutely in areas with good transit service

13. Some cities with aging infrastructure have seen a decrease in service quality due to insufficient funding to maintain infrastructure, causing delays and safety problems

All but one of the factors listed above are beyond the ability of transit to influence. Transit is more a recipient of circumstances than a catalyst that alters them. This contributes greatly to the difficulty in predicting transit's future in the United States. And this is to say nothing of the unpredictable nature of politics in the country. Republican administrations are generally not supportive of investment in public transit. Another concern is that the "new kid in town"-in this case automated and connected vehicles-will get all the attention and funding, while support for transit fades in light of new, exciting developments. Automated vehicles will also cause transit to lose one of its key advantages in terms of the value of travel time where passengers can be productive while traveling.

With all the changes that are taking place, the question now is whether the existing model of public transportation might soon become obsolete, at least in some areas. It has been said that the best way to predict the future is to invent it. TNCs seem to have followed this suggestion as they implement change in a manner recommended by Buckminster Fuller who said, "You never change things by fighting the existing reality. To change something, build a new model that makes the existing model obsolete."

Uber and Lyft have introduced a new reality created not by traditional transportation engineers and planners, but by computer scientists and venture capitalists who saw the opportunity to become major players in the vast field of transportation. Some transit advocates believe that TNCs will supplement public transit and enable more people to use it by possibly solving the first mile/last mile challenge or by providing mobility during hours transit is scant. Early results are not encouraging. TNCs can help solve the first mile/last mile challenge now, but transit ridership has declined in spite of this. A significant part of the challenge for transit agencies is that the competition is no longer limited to private automobile ownership and use. Now there are many more options for travelers.

However, not all is doom and gloom for public transit. The fundamental things still apply: transit has inherent advantages in dense urban areas where it is and will be the most space efficient method of moving people into and within major cities. It is unlikely more road space can be found within densely developed areas. Transit will continue to be essential to the functioning of economic agglomerations. Where transit provides advantages in terms of speed and price, it will be competitive and necessary, particularly in large cities.

Transit will continue to work best where automated vehicles might work the worst-in dense, complex urban street environments with double parked vehicles, truck deliveries, bikes, pedestrians, and buses. Most recent studies show that automated vehicles will increase vehicle miles traveled, causing potentially greater congestion. As Graham Currie asks in this issue, 
"Is a future with autonomous vehicles, including a proportion of them not carrying anyone, a realistic solution to high traffic volumes in congested areas?"

It should be noted that public transit has been a leader in automated vehicle operations, already providing such service in many rail systems around the world. Automated buses in mixed traffic provide a greater challenge to implement, but pilot projects are being conducted in various settings around the world. Should automated buses become safe and feasible, the savings realized from not needing bus operators could conceivably allow transit agencies to increase their service hours by $30-40 \%$, making transit a much more attractive alternative than it is today. Fully automated vehicles are likely to provide first mile/last mile transportation to and from fixed transit stops, making transit more accessible to more people. While this exists today in very limited demonstrations, it will almost certainly become ubiquitous. Like existing transit, it will be shared and accessible. While the first mile/last mile service has usually been associated with private companies such as TNCs, who is to say that transit agencies themselves would not be able to provide this service if they chose to do so? One future feature of autonomous first mile/last mile service is that the vehicles will be easily manufactured at low cost using 3D printers. With little operating cost and much lower capital costs, public transit could become a more attractive service, garnering considerably more ridership.

Here is an optimistic forecast for the future of public transit in the United States:

- Transit services will focus on areas and corridors of highest use with improved frequency and speed, resulting in increased ridership and revenues

- Areas of lower density will be served either through partners or possibly by public autonomous feeder vehicles helping to increase ridership and reduce costs

- Many paratransit users may use autonomous vehicles, thereby reducing transit agency expenses considerably

- Big data will enable better demand analysis for more precise resource allocation decisions

- More people will abandon car ownership and consider alternatives囚transit will be one of many choices that work seamlessly, with transit being the highest capacity form of shared mobility

- Real-time information will be even more powerful and useful to travelers and payment for service will be easier

- More transit-oriented developments with genuine transit-first purposes will be developed

- Priority will be given to rubber-tired transit on streets where appropriate, making bus transit safer, faster, and more attractive

- Automation will be introduced in new circumstances that warrant it (e.g., buses on dedicated lanes)

Here is a pessimistic forecast for the future of public transit in the United States:

- Population will continue to move to the suburbs where efficient transit is more difficult to provide 
- TNCs will be far more aggressive and improve their ability to carry multiple passengers at one time, causing public transit ridership and revenue to decline

- Ridership decline will continue, leading to a downward spiral of reduced revenues, reduced service, and further reduced ridership

- Transit expenses will continue to rise higher than inflation

- Automation will be resisted by transit unions, thereby denying the potential fiscal benefits that could accrue to transit agencies and the communities they serve

- The majority of new funding will go to the "new kid in town," automated vehicle infrastructure

Which of these two scenarios is more likely? Probably a bit of both, which begs the question of why transit is facing these challenges. Transit investment is reflective of a society's values. Riding transit is a collective activity: we are a country that tends to prefer personal freedom, liberty, and privacy. Americans are a people that have become quite spoiled by the most seamless trip of all-taking your car from your garage to the front step of wherever you are going. That might change if Mobility as a Service (MaaS) becomes a reality, where a variety of mobility options are available to us quickly and at a price that makes owning a car seem silly. We in the transportation community need to be more alert to the changes occurring in technology and societal attitudes so that we can promote transit where it is the most logical and best option. Here are just a few suggestions for future research:

- Do TNCs increase or decrease transit use?

- Will people ride in regular fixed route buses without drivers, particularly in dense urban areas?

- Is a system of subsidies feasible for lower income people to use TNCs?

- Where do private automated vehicles park if not in the downtown, and how will that affect vehicle miles traveled and traffic flow?

- Can transit agencies provide the same type of service as TNCs to feed their own system, and will that make sense?

- How will those without smartphones access these new types of services?

This special issue of the Journal of Transportation is dedicated to pondering the future of public transportation in the United States. It has been my goal as editor to make papers in the Journal more understandable to the operating managers of transit agencies, and this issue clearly meets that goal. I hope you enjoy it!

Tampa, Florida

February 2018 